ABDI: Jurnal Pengabdian dan Pemberdayaan Masyarakat ISSN: 2656-369X (Print), 2684-8570 (Online)

Volume 3 No. 1, Juni 2021

http://abdi.ppj.unp.ac.id/index.php/abdi

Email: abdi@ppj.unp.ac.id

DOI: https://doi.org/10.24036/abdi.v3il.94

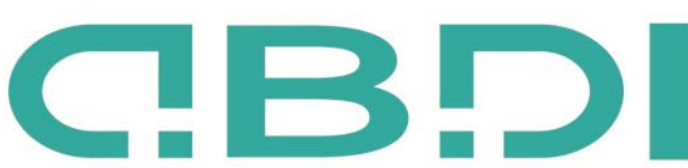

ABDI: JURNAL PENGABDIAN DAN PEMBERDAYAAN MASYARAKAT

\title{
Edukasi dan Latihan Peregangan Otot dalam Mengantisapi Keluhan Muskuloskletal Pada Penenun Tradisional
}

\author{
Maksuk Maksuk¹, Maliha Amin², Aguscik Jaya ${ }^{3}$ \\ ${ }^{1,2,3}$ Poltekkes Kemenkes Palembang
}

E-mail: maksuk@poltekkespalembang.ac.id, maliha@poltekkespalembang.ac.id,aguscik@poltekkespalembang.ac.id

\begin{abstract}
Abstrak
Keluhan muskuloskeletal paling sering dialami penenun disebabkan oleh posisi kerja yang tidak ergonomis dan statis dalam jangka waktu yang lama. Kondisi ini jika tidak diantisipasi dapat menimbulkan gangguan otot diantaranya nyeri punggung, sakit pinggang, nyeri bahu dan pergelangan tangan dan kaki. Latihan peregangan otot ini bertujuan untuk mengantisipasi keluhan muskuloskeletal pada penenun tradisional di sentra industri kain Kelurahan Tuan Kentang Kota Palembang. Metode pelaksanaan kegiatan yaitu edukasi tentang cara mengantisipasi keluhan muskuloskltetal dan latihan peregangan otot pada penenun tradisional di sentra kain tenun Kelurahan Tuan Kentang Palembang. Jumlah peserta yang mengikuti kegiatan ini sebanyak 30 penenun. Kegiatan ini dilaksanakan di sentra industri Tuan Kentang Kota Palembang pada tanggal $18-25$ Oktober 2020. Hasil evaluasi pengetahuan penenun diukur menggunakan evaluasi proses yaitu saat proses pemberian materi berlangsung dan evaluasi output yaitu dengan memberikan pertanyaan setelah kegiatan selesai, selanjutnya melatih gerakan peregangan otot ringan di tempat kerja. Penenun mengikuti kegiatan penyampaian materi dan latihan peregangan otot secara serius dan berkomitmen untuk melakukan peregangan setiap hari di tempat kerja sesuai jadwal.

Kata Kunci: Edukasi, Latihan peregangan otot, Keluhan muskuloskeletal, Penenun tradisional
\end{abstract}

\section{Abstract}

Musculoskeletal disorders that most often make weavers were caused by non-ergonomic and static position for a long period. If this condition is not anticipated, it can be caused musculoskeletal disorders such as back pain, shoulder pain, wrists and feet pain. This muscle stretching exercise was aimed to anticipate musculoskeletal disorders in traditional weavers at Tuan Kentang Palembang City. The methods of activityies were education about how to anticipate musculoskeletal disorders and muscle stretching exercises for traditional weavers. The number of participants was 30 weavers. This activity was carried out at the Tuan Kentang industrial center in Palembang City on October 18-25th, 2020. The results of the evaluation of the weaver's knowledge were measured using process evaluation, namely when the material giving process took place and output evaluation, namely by asking questions after the activity was completed, then practicing light muscle stretching movement at workplace. The weavers take material delivery and muscle stretching exercises seriously and commit to stretching every day at work according to schedule.

Keywords: Education, Musculoskeletal disorders, Stretching exercises, Traditional weavers

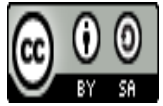

Received: 1 Februari, $2021 \quad$ Revised: 5 Mei $2021 \quad$ Available Online: 11 Mei 2021

\section{Pendahuluan}

Penilaian risiko kesehatan saat ini lebih difokuskan pada industri - industri menengah keatas, tetapi belum banyak dilakukan pada kelompok industri menengah kebawah terutama pada industri sektor informal termasuk kegiatan di sentra industri kain tenun. Salah satu kegiatan industri tenun pada sektor informal masih menggunakan peralatan secara tradisional dan manual atau dikenal dengan istilah Alat Tenun Bukan Mesin (ATBM) termasuk kegiatan di sentra industri kain tenun yang berpusat di Kelurahan Tuan Kentang Kota Palembang. 
Kota Palembang merupakan wilayah perkotaan yang banyak terdapat kegiatan ekonomi yang dilakukan oleh masyarakat dimana salah satunya adalah kegiatan industri penenunan kain yang dikenal dengan tenun songket dan tajung (blongket). Salah satu pusat industri tenun kain ini terletak di Kelurahan Tuan Kentang sebagai sentra tenun yang menghasilkan kain khas Palembang yang merupakan usaha kecil dan menengah yang memperkuat sektor industri di Kota Palembang, yang masih dikerjakan secara tradisional menggunakan Alat Tenun Bukan Mesin. Penggunaan Alat Tenun Bukan Mesin (ATBM) ini banyak digunakan di sentra industri kain tenun di beberapa daerah di Indonesia termasuk Kota Palembang (Shobur, Maksuk, Sari, 2019).

Berdasarkan hasil survei pendahuluan yang dilakukan penulis di sentra industri tenun yang terletak Kelurahan Tuan Kentang Kota Palembang ini terdapat 7 industri rumahan yang merupakan workshop yang memproduksi kain tenun secara tradisional. Kelompok industri ini dikenal dengan Griya Kain Tuan Kentang yang diketuai oleh Kelompok Usaha Bersama (KUB) Griya Kain Tuan Kentang. Hasil wawancara dengan pemilik Griya tenun terdapat sekitar 44 penenun, tekarena kondisi pandemi Covid hanya ada beberapa pekerja yang aktif. Kegiatan industri tenun di Kelurahan Tuan Kentang Kota Palembang ini merupakan kegiatan usaha yang dimiliki oleh kelompok masyarakat.

Aktivitas kegiatan menenun dilakukan setiap hari dimulai dari pukul 7.30 - 16.30 setiap harinya, kondisi ini menyebabkan penenun selalu berada pada posisi yang tidak ergonomis dan statis dalam waktu yang lama. Sikap kerja statis dalam jangka waktu yang lama dapat menimbulkan keluhan muskuloskltetal (Tarwaka \& Bakri, 2010). Beberapa faktor risiko yang dapat menyebabkan keluhan muskuskletal diantaranya umur, jenis kelamin, masa kerja dan lama kerja pada penenun tradisional (Shobur, Maksuk \& Sari, 2019). Keluhan muskuloskletal yang dialami penenun berhubungan dengan masa kerja (Butar-Butar, 2018) dan sikap kerja dan paling sering dialami penenun yaitu pada lengan, bahu dan kaki (Sandi, Ekawati \& Suroto, 2015)

Peregangan fisik merupakan salah satu latihan yang dilakukan di tempat kerja dimana saat ini dipromosikan oleh Kementerian Kesehatan RI dengan tujuan untuk mengantisipasi keluhan muskuloskletal dan kelelahan fisik pekerja. Latihan peregangan otot merupakan salah satu upaya administratif dalam mengurangi risiko bahaya ergonomi di tempat kerja (Anggraeni, 2015). Kegiatan ini bertujuan untuk mengantisipasi keluhan muskuloskletal pada pekerja tenun dengan cara edukasi dan latihan peregangan otot di ditempat kerja.

\section{Metode Pelaksanaan}

Metode yang digunakan untuk mengantisipasi keluhan muskuloskltetal yang dialami penenun yaitu dengan cara penyuluhan, diskusi dan tanya jawab, sedangkan latihan peregangan otot dilakukan dengan cara simulasi gerakan peregangan leher, bahu, tangan, punggung, pinggang dan kaki kepada penenun. Adapun media yang digunakan untuk melakukan gerakan peregangan berupa poster gerakan peregangan buku saku dengan judul "Antisipasi Keluhan Muskuloskeletal pada Penenun Tradisional." Sasaran dalam kegiatan ini adalah semua penenun yang merupakan kelompok pekerja di Griya Tenun Tuan Kentang sebanyak 30 penenun di masing - masing work station.

Kegiatan pengabdian masyarakat dilaksanakan pada tanggal 18 Oktober sampai dengan 25 Oktober 2020 di Griya Tenun yang terletak di Sentra Industri Kelurahan Tuan Kentang Kota Palembang. Pelaksana kegiatan pengabdian kepada masyarakat adalah Dosen DIII Keperawatan Palembang dibantu oleh Mahasiswa DIII Keperawatan Palembang. Pelaksanaan kegiatan dilakukan melalui tiga tahapan yaitu:

\subsection{Persiapan}

Pada tahap persiapan yang dilakukan sebagai berikut: (1) Perizinan kegiatan pengabdian kepada masyarakat ke Badan Kesbangpolinmas Kota Palembang dan Puskesmas Jaka Baring Kota Palembang. (2) Koordinasi dengan ketua kelompok kerja di sentra tenun Kelurahan Tuan Kentang Kota Palembang dan surveil lokasi kegiatan. (3) Menentukan dan menyepakati metode kegiatan yang digunakan saat pelaksanaan kegiatan pengabdian masyarakat dengan kelompok mitra. (4) 
Melakukan koordinasi dan persamaan persepsi dengan mahasiswa yang dilibatkan dalam kegiatan pengabdian kepada masyarakat.

\subsection{Pelaksanaan}

Pelaksanaan kegiatan yang dilakukan meliputi: (1) Penyampaian materi tentang Antisipasi Keluhan Muskuloskletal oleh Dosen DIII Keperawatan. (2) Simulasi/demonstrasi Latihan Peregangan Otot oleh dosen pelaksana kegiatan pengabdian masyarakat dibantu mahasiswa.

\subsection{Observasi dan Evaluasi}

Pada akhir kegiatan Pengabdian kepada Masyarakat peserta diberikan kesempatan untuk memperagakan kembali gerakan peregangan otot dengan benar. Selain itu peserta juga diberikan beberapa pertanyaan untuk dijawab secara langsung untuk mengetahui keberhasilan kegiatan yang telah dilakukan.

Kegiatan melatih gerakan peregangan otot kepada penenun dipergakan oleh Dosen dibantu mahasiswa DIII Keperawatan Palembang dan diikuti oleh penenun seperti pada Gambar 1 dibawah ini:

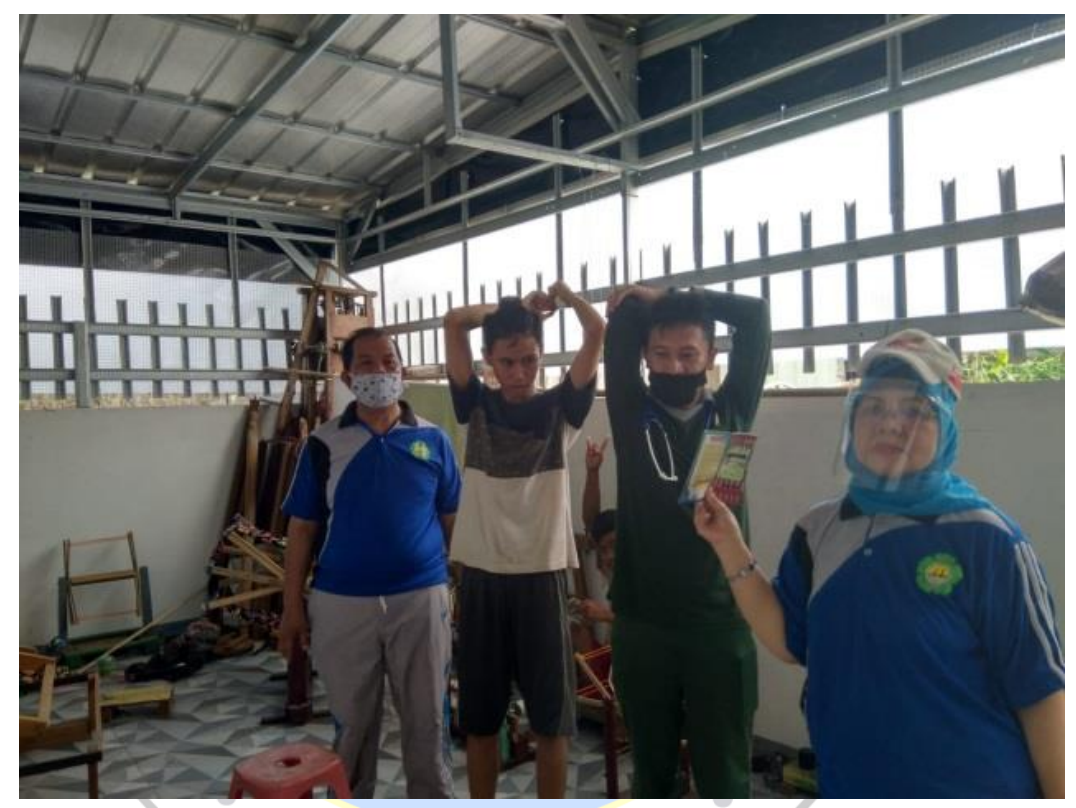

\section{Gambar 1. Melatih Gerakan Peregangan Otot pada Penenun}

Setelah melatih gerakan peregangan otot, sebagai bentuk evaluasi keberhasilan latihan peregangan yang telah diberikan, maka penenun diminta mengulangi gerakan peregangan otot yang telah diajarkan kepada mereka. Adapun bentuk evaluasinya adalah dengan meminta penenun untuk mengulangi kembali gerakan peregangan otot yang telah diajarkan seperti pada Gambar 2 dibawah ini. Kegiatan melatih gerakan peregangan otot kepada penenun dipergakan oleh Dosen dibantu mahasiswa DIII Keperawatan Palembang dan diikuti oleh penenun seperti pada Gambar 1 dibawah ini: 


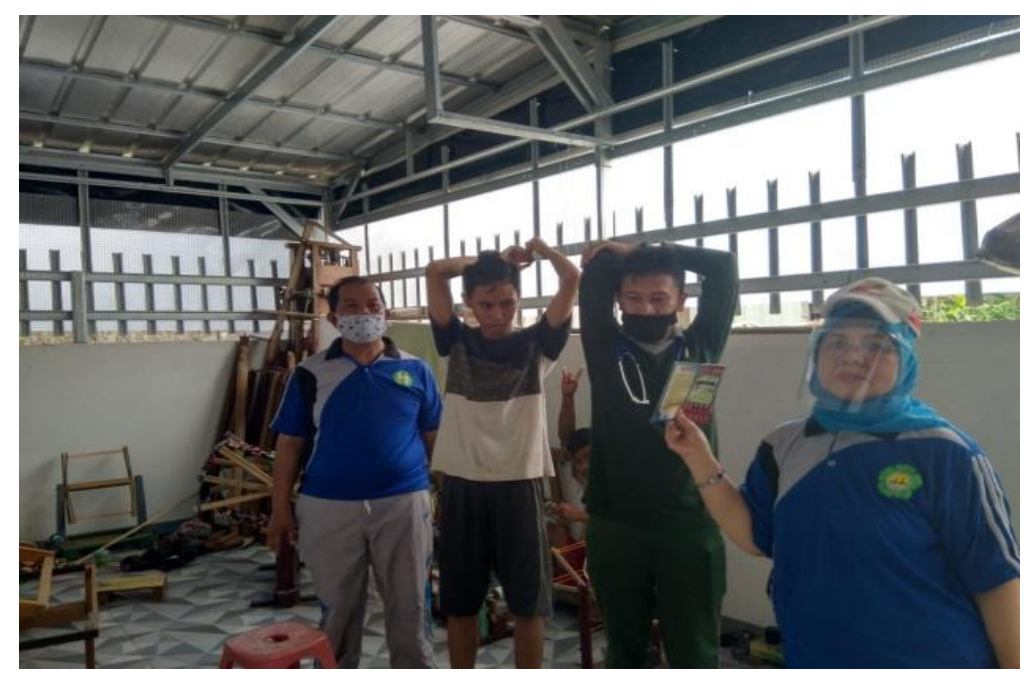

Gambar 2. Melatih Gerakan Peregangan Otot pada Penenun

Setelah melatih gerakan peregangan otot, selanjutnya penenun diminta mengulangi gerakan peregangan otot seperti pada Gambar 2 dibawah ini:

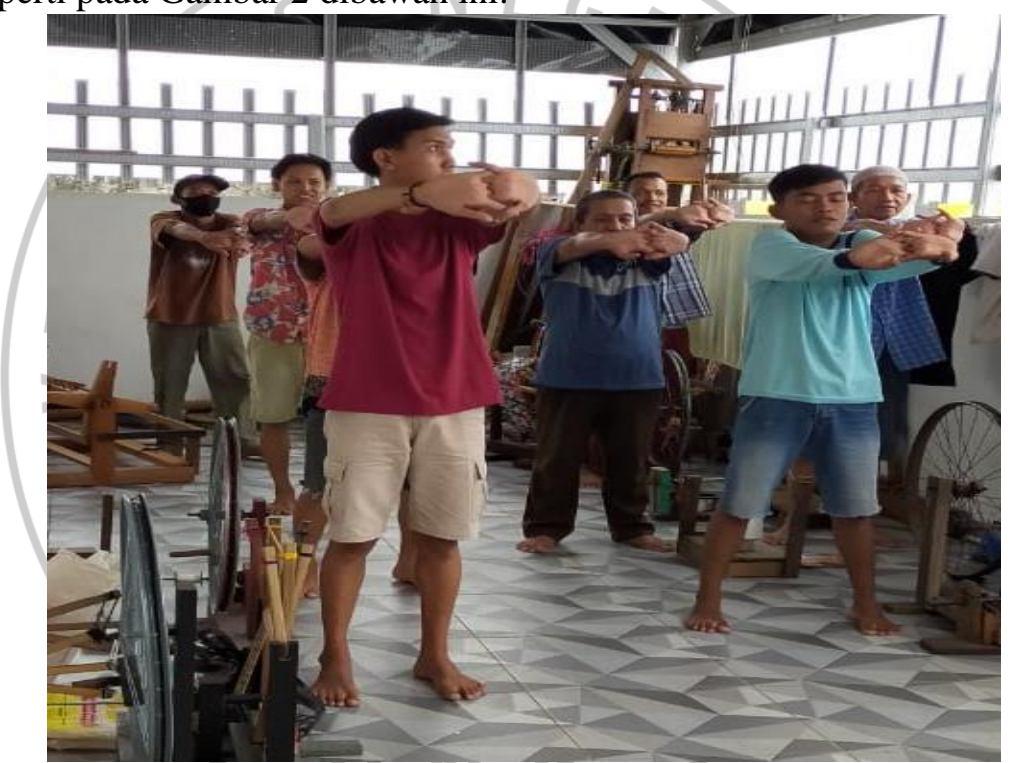

Gambar 2. Evaluasi Peragaan Latihan Peregangan Otot oleh Penenun

\section{Hasil dan Pembahasan}

\subsection{Hasil Analisis Pengetahuan Penenun Sebelum dan Setelah Edukasi}

Berdasarkan hasil pengukuran pengetahuan penenun melalui edukasi tentang Cara Mengantisipasi Keluhan Muskuloskletal pada Penenun adalah sebagai berikut:

Tabel 1. Pengetahuan Penenun Sebelum dan Setelah diberikan edukasi tentang Cara Mengantisipasi Keluhan Muskuloskletal ( $\mathrm{n}=30)$

\begin{tabular}{lccc}
\multicolumn{1}{c}{ Variabel } & Mean & SD & Nilai p \\
\hline $\begin{array}{l}\text { Pengetahuan Sebelum dan } \\
\text { Setelah Edukasi }\end{array}$ & 0,400 & 0,681 & 0,017 \\
\hline
\end{tabular}

Uji statistik: pair t test, SD: Standar Deviasi 
Berdasarkan Tabel 1. hasil analisis uji statistik menggunakan uji $\mathrm{T}$ berpasangan terhadap 30 penenun diperoleh nilai $\mathrm{p}=0,017$, ini berarti ada peningkatan pengetahuan penenun sebelum dan setelah dilakukan edukasi terkait cara mengantisipasi keluhan muskuloskletal. Hasil wawancara kepada penenun sebelum dilakukan edukasi secara umum penenun belum mengetahui bagaimana cara mengatasi keluhan muskuloskletal. Setelah dilakukan edukasi menggunakan buku saku tentang cara mengatasi keluhan muskuloskletal pengetahuan penenun meningkat secara signifikan. Pemberian edukasi merupakan salah satu metode yang dapat dilakukan untuk meningkatkan pengetahuan masyarakat termasuk salah satunya pada kelompok penenun. Edukasi merupakan upaya pembelajaran kepada masyarakat agar mau melakukan tindakan-tindakan untuk memelihara dan meningkatkan kesehatan (Notoatmodjo, 2007). Edukasi terkait sikap kerja ergonomi dapat memberikan kemudahan bagi para pekerja sehingga dapat mengatasi kendala dan keterbatasan saat bekerja (Nugraha, Antari \& Saraswati, 2019).

\subsection{Hasil Evaluasi Keluhan Muskoloskeletal}

Berdasarkan hasil evaluasi dengan penenun setelah melakukan peregangan otot keluhan Muskuloskeletal berkurang terutama pada pegal pada bahu, leher, tangan, pinggang dan punggung berkurang dan penenun mempraktikkan gerakan tersebut di tempat kerja secara rutin. Keluhan MSDs yang paling banyak dialami penenun yaitu nyeri pada punggung, sakit pinggang, sakit pada bahu, tengkuk/leher dan pergelangan tangan (Shobur, Maksuk \& Sari, 2019). Selain itu, keluhan paling banyak dirasakan oleh pekerja berhubungan dengan masa kerja yang relatif lama dan pada pekerja wanita. Kondisi ini disebabkan oleh keluhan muskuloskletal berhubungan dengan masa kerja (Nuryaningtyas, Binarfika \& Martiana, 2014). Peregangan yang dilakukan secara teratur oleh pekerja pada bagian divisi Garment Sukoharjo dapat mengurangi ketegangan otot (Anggriawan \& Sri Darnoto, 2016).

Kondisi ini disebabkan oleh pekerja yang melakukan gerakan yang berulang-ulang dan duduk pada posisi yang statis dan dalam waktu yang lama setiap harinya dan terjadi akibat menerima tekanan akibat beban kerja secara terus menerus tanpa memperoleh kesempatan untuk relaksasi (Tarwaka \& Bakri, 2010). Latihan peregangan dinamis dan istirahat aktif terbukti berpengaruh terhadap penurunan keluhan muskuloskeletal pada pekerja bagian pengendalian mutu produk dan sablon di industri Garmen Adhi Fashion (Nooryana, Adiatmika \& Purnawati, 2020). Latihan peregangan otot yang dilakukan oleh penenun tradisional Sarung Samarinda di tempat kerja juga dapat menurunkan keluhan Muskuloskeletal (Ramdan \& Azahra, 2020).

Target capaian dalam kegiatan ini yaitu pekerja mampu melakukan latihan peregangan otot di tempat kerja secara mandiri dan menjadikan kegiatan ini sebagai rutinitas yang harus dilakukan. Dukungan dan peran aktif ketua kelompok griya tenun dan pekerja memberikan kemudahan dalam memaksimalkan pengetahuan dan perubahan perilaku di lingkungan tempat mereka bekerja. Hal ini dibuktikan dengan semua pekerja dan ketua kelompok sangat antusias dalam mengikuti kegiatan pengabdian masyarakat yang dilakukan dan meminta kembali agar kegiatan ini dapat rutin dilakukan. Dalam kegiatan ini juga diberikan banner latihan peregangan oto yang dipasang di setiap work station dan buku saku" Antisipasi Keluhan Muskuloskletal pada Penenun Tradisional," kepada semua pekerja dan ketua kelompok kerja.

Dengan demikian, dapat disimpulkan bahwa semua pekerja dan ketua tim dari masing masing work station menyambut positif dan antusias dalam mengikuti penyuluhan dan pelatihan peregangan fisik dalam mengatasi keluhan muskuloskletal serta akan mempraktikannya secara rutin sebagai suatu budaya kesehatan di tempat kerja. Kegiatan ini menurut Ketua Tim Kelompok Mitra mampu meminimalisir gangguan kesehatan terutama keluhan muskuloskletal yang dialami pekerja selama melakukan kegiatan menenun.

\section{Kesimpulan}

Berdasarkan hasil dan dampak kegiatan diatas, maka kesimpulan dari kegiatan ini adalah sebagai berikut: (1) Pengetahuan penenun tentang cara mengantisipasi keluhan muskuloskletal meningkat secara signifikan, ini dibuktikan dengan kemampuan peserta menjawab pertanyaan yang 
diajukan saat proses edukasi berlangsung. (2) Pekerja dan ketua tim dari masing - masing workstation berkomitmen untuk mempraktikkan dan membudayakan peregangan otot di tempat kerja setiap hari sesuai waktu yang telah ditentukan. (3) Hasil evaluasi proses pelaksanaan kegiatan pengabdian kepada masyarakat, secara umum berjalan dengan baik ini dibuktikan dengan Ketua Kelompok Kerja memberikan apresiasi dan sambutan yang sangat baik terhadap kegiatan yang dilakukan oleh Tim Pelaksana yang belum mereka dapatkan sebelumnya. Sebagai rekomendasi yang dapat diberikan oleh Tim pelaksana kegiatan pengabdian kepada masyarakat ini yaitu agar pekerja tetap melaksanakan kegiatan peregangan otot ini di tempat bekerja dan menjadikan kegiatan ini sebagai budaya di tempat kerja.

\section{Daftar Pustaka}

Anggraeni, R. R. (2015). Manfaat Peregangan Otot Terhadap Keluhan Nyeri Punggung Bawah Pada Pekerja Bagian Knitting Gantung PT. Royal Korindah Purbalingga. Skripsi. Universitas Negeri Semarang.

Anggriawan, R., \& Sri Darnoto, S. K. M. (2016). Pengaruh Pemberian Peregangan Otot (Stretching) Terhadap Keluhan Muskuloskeletal Dan Kejenuhan Pada Pekerja Bagian Menjahit Divisi Garment Di Pt. Tyfountex Indonesia Sukoharjo Tahun 2016. Skripsi Universitas Muhammadiyah Surakarta.

Butar-Butar, E. S. (2018). Faktor-Faktor Yang Mempengaruhi Keluhan Musculoskeletal Disorders (MSDs) Pada Pekerja Tenun Ulos Di Kecamatan Siantar Selatan Kota Pematang Siantar Tahun 2017. Skripsi. Universitas Sumatera Utara

Nooryana, S., Adiatmika, I. P. G., \& Purnawati, S. (2020). Latihan Peregangan Dinamis dan Istirahat Aktif Menurunkan Keluhan Muskuloskeletal Pada Pekerja di Industri Garmen. Jurnal Ergonomi Indonesia (The Indonesian Journal Of Ergonomic), 6(1), 61-67.

Nuryaningtyas, B. M., \& Martiana, T. (2014). Analisis Tingkat Risiko Muskuloskeletal Disorders (Msds) Dengan The Rapid Upper Limbs Assessment (RULA) Dan Karakteristik Individu Terhadap Keluhan Msds. The Indonesian Journal Of Occupational Safety And Health, 3(3), 160-169.

Nugraha, M. H. S., Antari, N. K. A. J., \& Saraswati, N. L. P. G. K. (N.D.). (2019). Efektivitas Penerapan Edukasi Sikap Kerja, Elektroterapi Dan Terapi Latihan Untuk Penderita Mechanical Neck Pain. Jurnal Ergonomi Indonesia (The Indonesian Journal of Ergonomic), 5(2), 83-89.

Sandi, P. R., Ekawati, E., \& Suroto, S. (2015). Pengaruh Karakteristik Pekerja Terhadap Kejadian Musculoskeletal Disorder Pada Pekerja Pabrik Tenun Masari Pemalang. Jurnal Kesehatan Masyarakat (E-Journal), 3(1),429-436.

Ramdan, I. M., \& Azahra, A. (2020). Menurunkan Keluhan Gangguan Muskuloskeletal Pada Penenun Tradisional Sarung Samarinda Melalui Pelatihan Peregangan Otot Di Tempat Kerja. Jurnal Abdimas BSI: Jurnal Pengabdian Kepada Masyarakat, 3(2), 109-117.

Shobur, S., Maksuk, M., \& Sari, F. I. (2019). Faktor Risiko Musculoskeletal Disorders (Msds) Pada Pekerja Tenun Ikat Di Kelurahan Tuan Kentang Kota Palembang. Jurnal Medikes (Media Informasi Kesehatan), 6(2), 113-122.

Soekidjo, N. (2007). Promosi Kesehatan Dan Ilmu Perilaku. Jakarta: Rineka Cipta, 57-68.

Tambun, M. S. (2012). Analisis Risiko Ergonomi Dan Keluhan Musculoskeletal Disorder (MSDs) Pada Pekerja Tenun Ulos Di Kelurahan Martimbang Dan Kelurahan Kebun Sayur Kota Pematan Siantar Tahun 2012. Depok: Universitas Indonesia.

Tarwaka, P., \& Bakri, L. S. (2010). Ergonomi Industri Dasar-Dasar Pengetahuan Ergonomi Dan Aplikasi Di Tempat Kerja. Surakarta: Harapan Press. 